\title{
Continual Green-Fluorescent Protein Monitoring of Cauliflower Mosaic Virus 35S Promoter Activity in Nematode-Induced Feeding Cells in Arabidopsis thaliana
}

\author{
Peter E. Urwin, Simon G. Møller, Catherine J. Lilley, Michael J. McPherson, and Howard J. Atkinson \\ Centre for Plant Biochemistry and Biotechnology, University of Leeds, Leeds LS2 9JT, UK \\ Received 25 July 1996. Accepted 8 January 1997.
}

\begin{abstract}
The responsiveness of the cauliflower mosaic virus $35 \mathrm{~S}$ promoter in feeding sites developed by both sexes of Heterodera schachtii and female Meloidogyne incognita has been studied. The objective was to establish the value of green-fluorescent protein (GFP) as a nondestructive reporter gene system for characterizing promoter activity at nematode feeding sites in vivo. Growth units were devised that allowed individual feeding sites in roots of Arabidopsis thaliana to be observed by both bright-field and epifluorescent illumination. Changes in GFP expression were visually observed under experimental conditions that resulted in chloroplast formation in syncytia but not other root cells. Changes in GFP levels altered the extent of quenching, by this protein, of red light emitted by chlorophyll within the chloroplasts under violet excitation. Image analysis provided a semiquantitative basis for simultaneous measurement of changes in GFP fluorescence and the unquenched emission by chlorophyll. GFP levels were constant in cells surrounding the syncytium induced by $\boldsymbol{H}$. schachtii, but they fell progressively from 10 to 35 days postinfection within this structure. Significant reduction in GFP levels was not limited to the early part of the time course but also occurred between 27 and 35 days postinfection. GFP was detected by immunoblotting in females of $M$. incognita but not in $H$. schachtii parasitizing similar GFP-expressing roots.
\end{abstract}

Additional keywords: regulation, transgenic.

Nematodes represent a key threat to modern agricultural practice (Atkinson 1995). The obligate sedentary endoparasitic nematodes, which comprise the root-knot nematodes (Meloidogyne spp.) and cyst nematodes (including Globodera and Heterodera spp.), are the most agronomically important groups. Root-knot nematodes invade close to root meristems and migrate through the root in an intercellular manner before establishing feeding sites adjacent to differentiating vascular tissue. These feeding sites comprise a system of giant cells surrounded by characteristically galled cortical root tissue. Each giant cell is formed by repeated nuclear division of a single cell without concomitant cytokinesis (Sijmons et al.

Corresponding author: Howard J. Atkinson.
1994). By contrast, cyst nematodes normally invade in the zone of root elongation and migrate in an intracellular manner, with concomitant destruction of plant cells, before initiating a single feeding cell, a syncytium, usually from a parenchymal cell within the stele. The syncytium is formed by the dissolution of adjacent parenchymal cell walls and the fusion of cell contents (Sijmons et al. 1994). Both giant cells and syncytia are highly specialized structures adapted to provide a nutrient sink from which the nematode is able to feed in an intermittent manner. Such adaptation of a plant cell to provide a nematode feeding cell involves significant alteration of normal plant gene expression (Hammond-Kosack et al. 1989).

Control of nematodes currently relies on three principal approaches: chemicals, cultural practices, and resistant varieties, often used in an integrated manner (Hague and Gowen 1987). However, the level of control provided by such conventional procedures is often inadequate to deal with the problem. This offers an important opportunity for plant biotechnology to produce effective and durable forms of nematode control with consequent reduction in environmental damage.

The identification of a promoter used to express a novel product that disrupts some aspect of nematode parasitism is a basic requirement of a molecular approach to nematode control. The wound-responsive promoter, wun-1, from potato responds to intracellular root migration by Globodera pallida but not to the less damaging intercellular migration of Meloidogyne spp. (Hansen et al. 1996). Several genes which show some degree of feeding-cell-specific expression, after the parasite has become established, have been reported (Gurr et al. 1991; Van der Eycken et al. 1996; Lambert and Williamson 1993; Wilson et al. 1994; Bird and Wilson 1994; Opperman et al. 1994).

We recently reported an anti-feedant approach to nematode control (Atkinson 1993; Urwin et al. 1995). This may provide a generic defense against nematodes through the use of promoters which express in a constitutive or root-specific manner (Atkinson and Lilley 1997). We demonstrated that transgenic delivery of an engineered rice cysteine proteinase inhibitor (Oc-I $\Delta$ D86) modified from oryzacystatin-I (Oc-I) had a major effect on disrupting the growth and development of G. pallida on tomato hairy roots (Urwin et al. 1995) and of Heterodera schachtii and Meloidogyne incognita on Arabidopsis (P. E. Urwin, unpublished). These studies used the cauliflower mo- 
saic virus (CaMV) 35S promoter to direct expression of the Oc-I $\Delta$ D86 inhibitor protein. GUS expression studies have previously suggested that the CaMV $35 \mathrm{~S}$ promoter is strongly down-regulated by $H$. schachtii and $M$. incognita (Goddijn et al. 1993). This result contrasts with our demonstration that CaMV 35S provides a useful level of nematode control. Since correct spatial and temporal promoter activity is central to the successful delivery of a defense, we investigated the expression pattern of the $\mathrm{pBI} 121$-derived CaMV $35 \mathrm{~S}$ promoter used in our constructs.

We describe a novel growth system for Arabidopsis thaliana, which allows the continual in vivo microscopic analysis of plant roots and provides a convenient system for following the fate of individual nematodes. We have used this system to monitor the growth and development of both $H$. schachtii and $M$. incognita and the consequent effects on the level of expression of CaMV $35 \mathrm{~S}$ using the green-fluorescent protein (GFP) reporter gene. We also demonstrate uptake of GFP during feeding by $M$. incognita, but not by $H$. schachtii.

\section{RESULTS}

\section{Plant growth and nematode development.}

Arabidopsis plants developed and flowered in growth units like the one illustrated in Figure 1 over a time period similar to that of plants grown in parallel in magenta pots. The nematode infection rate for both $H$. schachtii and $M$. incognita was approximately $15 \%$ of the juveniles with which roots had been inoculated. Their parasitic development progressed at a rate similar to that reported previously (Sijmons et al. 1991), and high numbers of eggs were associated with females within 35 days of inoculation. Eggs were extruded from the vulva of fe-

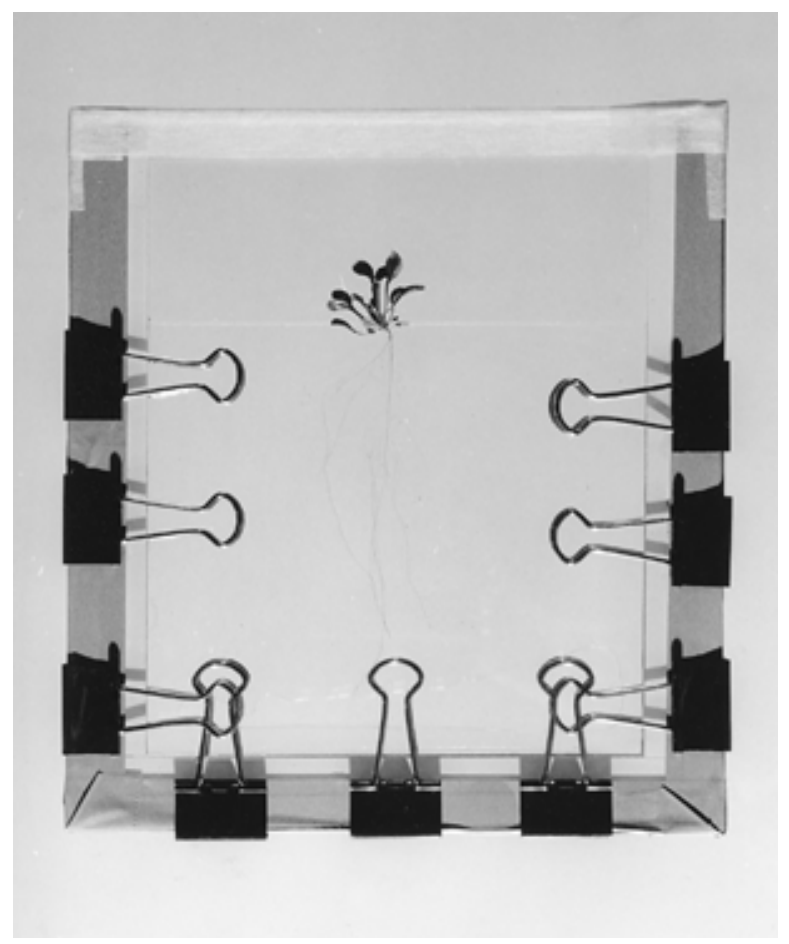

Fig. 1. Growth unit used to allow the continual observation of greenfluorescent protein expression in Arabidopsis roots. male $H$. schachtii at 28 days postinfection (p.i.), and body wall tanning had commenced for many individuals at 35 days p.i. Egg masses of $M$. incognita were first apparent at 25 days p.i. The development of identified individuals could be followed in the growth units, and their sex could be determined retrospectively when sexual dimorphism was evident. The shape factor of roundness describes the outline of the nematode. The roundness value is calculated from the ratio of perimeter squared to area, with a minimum value of unity for a circle. For $H$. schachtii, changes in shape gave roundness values of 4.44 and 2.4 for the female at 7 and 10 days p.i. and values less than 2 at 14 days p.i. and afterward. Roundness values less than 2 are characteristic of developing fourth-stage juvenile or adult females rather than other juvenile stages or adult males (Atkinson et al. 1996). The development of $H$. schachtii females was observed from 7 to 35 days p.i., and that of $M$. incognita females from 7 to 40 days p.i. One representative individual of each species was photographed: $H$. schachtii at 7, 10, 14, and 35 days p.i. and M. incognita at 28 days p.i. Female $H$. schachtii induced the formation of syncytia with the long, thin outlines that characterize parasitism of this host (Sijmons et al. 1991). The syncytium was evident as a yellow green region under bright-field illumination from 10 days p.i., and this facilitated the measurement of its outline at each time point. The extent of the syncytium at 14 days p.i. is indicated by asterisks in Figure $2 \mathrm{~L}$ and M. Once the syncytium had become established, by 10 days p.i., no significant increase in its outline area was subsequently observed. Its yellow green coloration was due to a low density of chloroplasts, which can develop in syncytia in response to limited exposure to light but were absent elsewhere in these roots and those of uninfected GFP-expressing or wild-type plants under the same growth conditions. Syncytia with a green coloration under bright-field illumination were not usually associated with juveniles that became male, but in a few individuals a green area was evident in the vicinity of the head (Fig. 2Z). A representative male was photographed from 7 days p.i. (Fig. $2 \mathrm{P}-\mathrm{W})$. It emerged from its cuticle and left the site of study between 17 and 21 days p.i.

\section{Expression of GFP in uninfected root tissue.}

GFP expression in roots was observed using epifluorescence with a violet excitation filter and a long-band-pass emission filter for frequencies greater than $495 \mathrm{~nm}$. Under these conditions an untransformed root of Arabidopsis with an established female $H$. schachtii grown in the dark was barely visible under the photographic conditions used later (Fig. 2E). The emerald green fluorescence emission present in Figure 2D is due to excitation of GFP in the roots of an uninfected transformed plant. Chloroplasts emit red fluorescence when excited by violet light, as observed by Sheen et al. (1995). This effect is shown by a root of a wild-type Arabidopsis plant grown in the light specifically to stimulate chloroplast formation (Fig. 2B). The high chloroplast density colored the roots green under bright-field illumination (Fig. 2A). A root of a transformed plant expressing GFP and grown in the light also appears green from chloroplast formation when viewed under the same conditions (Fig. 2C), but the emission of red fluorescence from the chloroplasts under violet excitation was completely quenched by the strong emerald green emission of GFP (Fig. 2D). 
Expression of GFP in roots infected with $\boldsymbol{H}$. schachtii.

Figure $2 \mathrm{H}-\mathrm{O}$ shows a developmental time course of a typical female $H$. schachtii on a root expressing GFP under the control of the CaMV 35S promoter at 7, 10, 14, and 35 days p.i. The photographs are paired images under bright-field and fluorescence illumination. Each shows a length of root containing a nematode and its feeding site (ir) plus an adjacent noninfected root (nr) of the same plant as a positive control
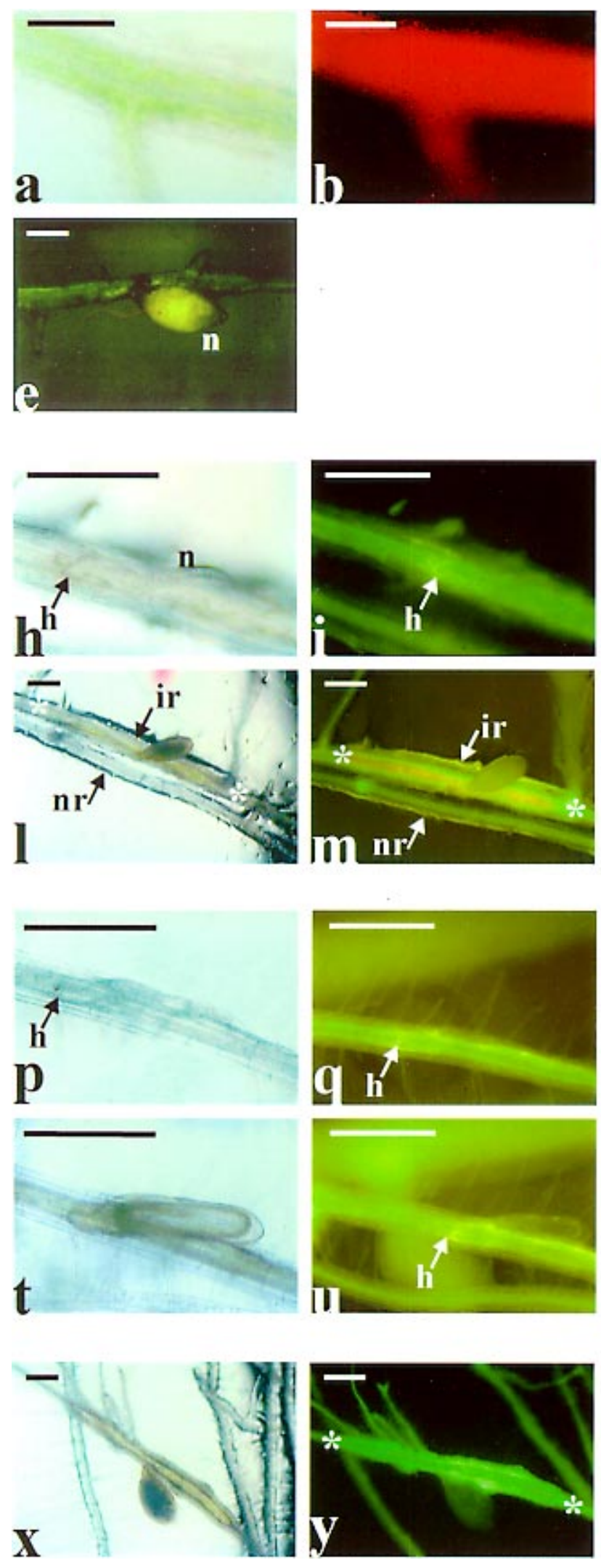
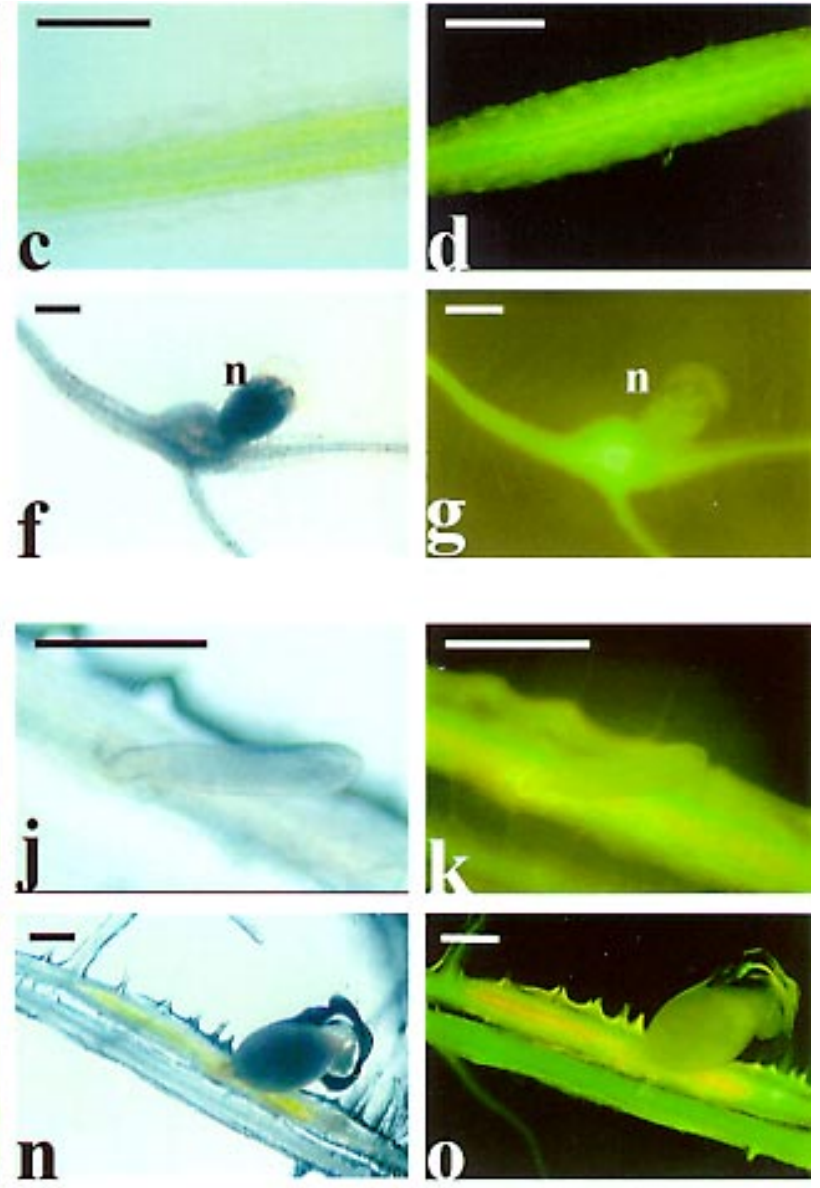

r
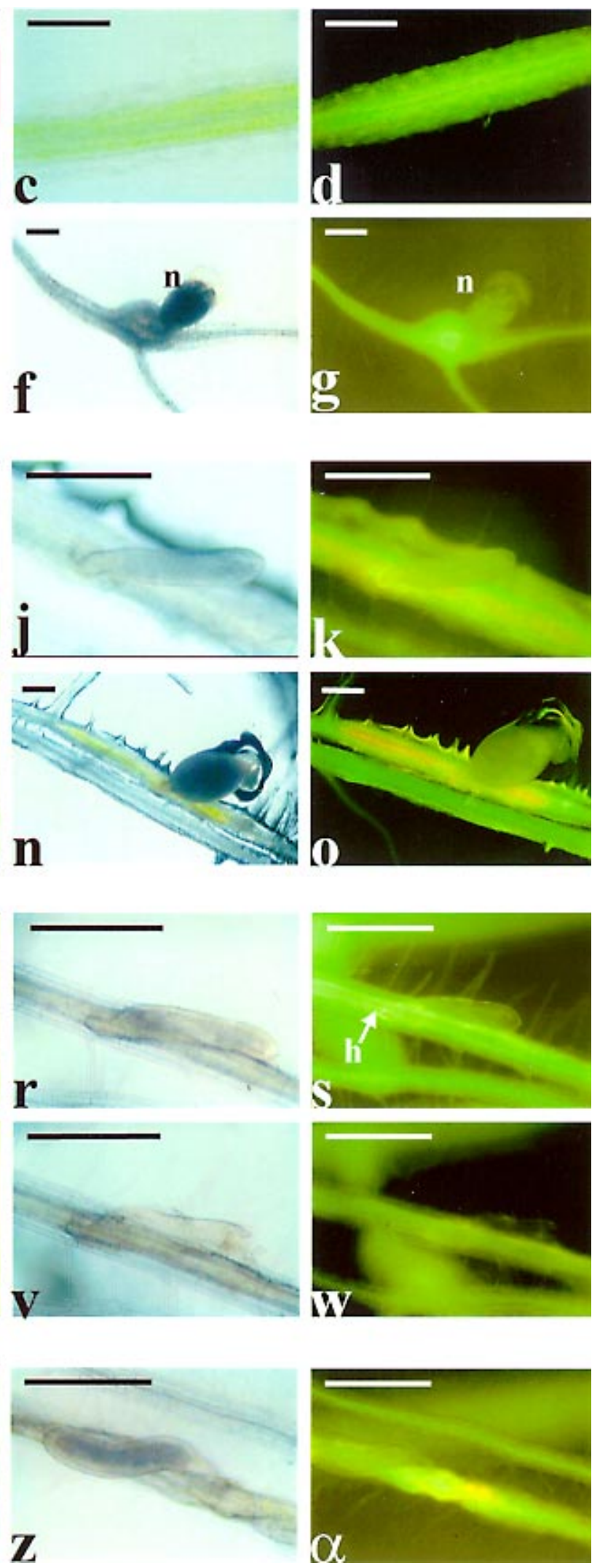
(Fig. 2L and M). In the fluorescent images, the expression of GFP appears as an emerald green coloration. There is very limited autofluorescence in the plant roots, as shown earlier (Fig. 2E).

At 7 days p.i., the head was already positioned as later. This indicates that the syncytium had been initiated, but changes in its GFP level had not resulted from initial parasite establishment. The area of root exhibiting a faint yellow fluorescence around the body of the nematode in Figure 2I is consistent with a limited response of plant cell walls following invasion. The presence of chloroplasts was used as a basis for detecting the outline of the syncytium. It also allowed changes in GFP expression within the syncytium to be readily observed. A syncytium containing chloroplasts at low density is intense green when viewed under violet light if GFP is present at a high level. However, it has a red or orange yellow coloration if GFP is not present at sufficiently high levels to quench the chloroplast emissions completely. Therefore a change in the coloration of a syncytium is expected if CaMV $35 \mathrm{~S}$ is downregulated and appreciable expression of GFP is lost. This effect allowed the syncytium formed by a female $H$. schachtii to be detected by a faint orange red fluorescence at 10 days p.i. The intensity of this coloration was more fully apparent from 14 to 35 days p.i. The loss of GFP expression was restricted to the syncytium and did not spread to adjacent root tissue during the course of the experiment. Figure $2 \mathrm{X}$ and $\mathrm{Y}$ shows a different female nematode, which was first examined at 21 days p.i. In this case the syncytium had not developed chloroplasts, since the roots had not previously been exposed to light, and in the absence of the associated red autofluorescence a reduction in green GFP fluorescence can be directly observed.

Male $H$. schachtii did not normally influence GFP expression to the extent of a visible color change during their development. A time course of a representative male is shown in Figure $2 \mathrm{P}-\mathrm{W}$. The limited yellow coloration, particularly evident in Figure 2U, is again associated with cell walls. Occasionally, down-regulation by a male did influence coloration around the head of the animal (the orange area in Fig. $2 \alpha$ ), but this was extremely limited in comparison to the effect induced by females.

\section{Analysis of GFP levels within a syncytium.}

Image analysis using a color camera allowed individual mean gray levels to be determined for both the green and the red components of each fluorescent image. This was used to confirm that the interpretation of color changes observed by eye was reliable. Measurements were taken in an area in the light path either adjacent to or within the syncytium in 10 dif- ferent roots parasitized by female nematodes (including the root shown in Fig. $2 \mathrm{H}-\mathrm{O}$ ) over a time course from 7 to 35 days p.i. At 7 days p.i. the outline of the syncytium was not well defined, and syncytial measurements were taken from an area of the root adjacent to the head of the nematode. Values on a linear scale of 0 to 255 were derived, representing increasing intensity of fluorescence in the green and red components of the light detected by the color camera. The mean values of these measurements are given in Figure 3. Linear regression established that the green component of the fluorescence from regions adjacent to the syncytium did not significantly change from 7 to 25 days p.i. (Fig. 3A). In contrast, the negative slope of the regression line for green emissions from the light path that included the syncytium established a significant fall in intensity over the period of measurement ( $t$ test on slope, $P<0.001)$. Furthermore, the intensity of green light was lower at 35 days p.i. than at 27 days p.i. and all earlier time points (one-way ANOVA, a priori contrasts, $P<0.001$ ). Therefore, a decline in emissions from GFP was detected between 27 and 35 days p.i., and the change was not restricted to the early period of the time course. The intensity of red emissions from cells around the syncytium was consistently low throughout the time course (Fig. 3B). This is consistent with the lack of chloroplasts in these cells. In contrast, the changes in red emissions establish that chlorophyll concentrations increased from 7 to 14 days p.i. and then remained at this higher level for the remainder of the time course. A curve was fitted to this changing pattern using polynomial regression.

\section{Expression of GFP in roots infected with $M$. incognita.}

No down-regulation of the CaMV $35 \mathrm{~S}$ promoter was observed in response to infection by the female root-knot nematode $M$. incognita (Fig. 2F and G). Every gall appeared to express GFP at a high level, and the fluorescence was intense. GFP emissions from the gall tissue tended to mask emissions from the centrally lying giant cells. However, the giant cells shown in Figure $2 \mathrm{~F}$ do seem to be associated with the intense emission evident in Figure 2G.

\section{Uptake of GFP by $H$. schachtii and $M$. incognita.}

We have recently shown by Western blot analysis that both $H$. schachtii and $M$. incognita are capable of ingesting the cystatin Oc-I $\Delta$ D86, a protein of $11.2 \mathrm{kDa}$ (P. E. Urwin et al., unpublished). Definition of the upper size limit of proteins that can be ingested by nematodes is important both for understanding nematode nutrition and digestive processes and for design of molecules for nematode control. The availability of GFP-expressing plants has allowed us to determine if nema-

Fig. 2. Activity of the cauliflower mosaic virus (CaMV) 35S promoter analyzed by fluorescence of green-fluorescent protein (GFP) in Arabidopsis infected with Heterodera schachtii and Meloidogyne incognita. A and B, Bright-field and fluorescent images, respectively, of a typical wild-type C24 Arabidopsis root grown in the light. C and D, Bright-field and fluorescent images, respectively, of a typical GFP-transformed Arabidopsis root grown in the light. E, Fluorescent image of a wild-type C24 Arabidopsis root infected with female H. schachtii and grown in the dark. F and $\mathbf{G}$, Bright-field and fluorescent images, respectively, of a typical $M$. incognita female at 28 days postinfection (p.i.) on a plant expressing GFP. H-O, Paired bright-field and fluorescent images showing the effect of a typical female $H$. schachtii on GFP expression at 7 days p.i. ( $\mathbf{H}$ and $\mathbf{I}), 10$ days p.i. (J and $\mathbf{K}), 14$ days p.i. $(\mathbf{L}$ and $\mathbf{M})$, and 35 days p.i. ( $\mathbf{N}$ and $\mathbf{O}$ ). Asterisks in $\mathbf{L}$ and $\mathbf{M}$ indicate the extent of the syncytium. $\mathbf{P}-\mathbf{W}$, Paired bright-field and fluorescent images showing the effect of a typical male $H$. schachtii on GFP expression at 7 days p.i. (P and $\mathbf{Q}), 10$ days p.i. (R and $\mathbf{S}$ ), 14 days p.i. (T and $\mathbf{U})$, and 21 days p.i. $(\mathbf{V}$ and $\mathbf{W}$ ). $\mathbf{X}$ and $\mathbf{Y}$, Effect of a female $H$. schachtii on GFP expression in a plant grown in the dark. The syncytium has not developed chloroplasts, resulting in the absence of red autofluorescence when it is viewed under violet light. The extent of the syncytium, in which lowered GFP expression is evident, is marked with asterisks. $\mathbf{Z}$ and $\alpha$, Effect of a male $H$. schachtii in which localized down-regulation of the CaMV $35 \mathrm{~S}$ promoter can be observed in $\alpha$ as an orange area adjacent to the head of the nematode. The bars represent $100 \mu \mathrm{m}$ in $\mathbf{A}-\mathbf{D}$ and $300 \mu \mathrm{m}$ in $\mathbf{E}-\alpha . \mathrm{n}=\mathrm{Nematode} ; \mathrm{h}=$ head of nematode; ir = infected area of root; $\mathrm{nr}=$ noninfected area of a second root. 

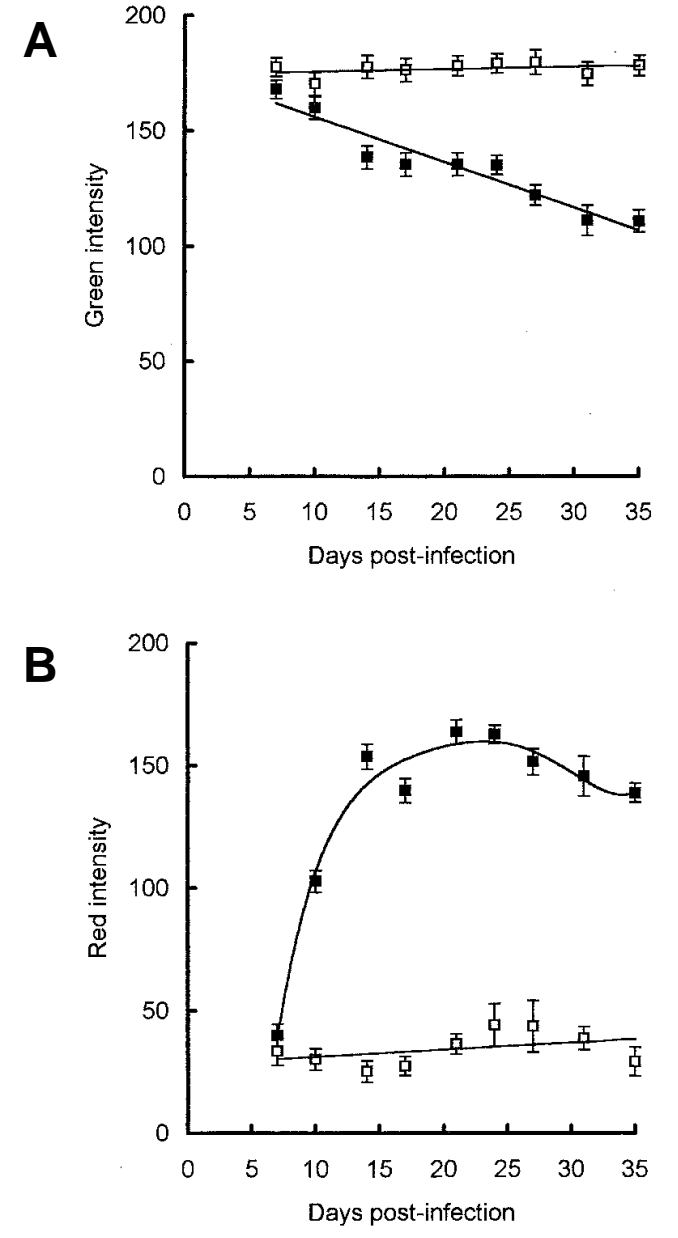

Fig. 3. Image analysis of the mean red and green components of fluorescent images of an Arabidopsis root transformed with green-fluorescent protein, viewed under fluorescent conditions. A, $\boldsymbol{\square}=$ Mean level of green emissions from inside the syncytium; $\square=$ mean level of green emissions from outside the syncytium. B, $\mathbf{\square}=$ Mean level of red emissions from inside the syncytium; $\square=$ mean level of red emissions from outside the syncytium. Values are means \pm SE.

todes are able to take up the larger GFP (28 kDa). Western blot analysis demonstrated the presence of GFP in $M$. incognita but failed to detect the protein in H. schachtii (Fig. 4).

\section{DISCUSSION}

The time course for the development of $H$. schachtii and $M$. incognita in growth units used for this work is similar to that on $A$. thaliana grown in conventional containers by Sijmons et al. (1991). The syncytium induced in roots of $A$. thaliana by $H$. schachtii reached a maximum size in outline at 10 days p.i. and had the elongated outline described previously (Sijmons et al. 1991). The results establish that the observation growth units allow time-course studies of the parasite and its feeding site by both bright-field and epifluorescence microscopy. This has particular value for studying changes in promoter activity in planta with GFP as a reporter. Both up- and down-regulation of promoters occurs in nematode feeding cells and has been reported in previous work (Goddijn et al. 1993). The GFP reporter system has the advantage of not requiring the de-

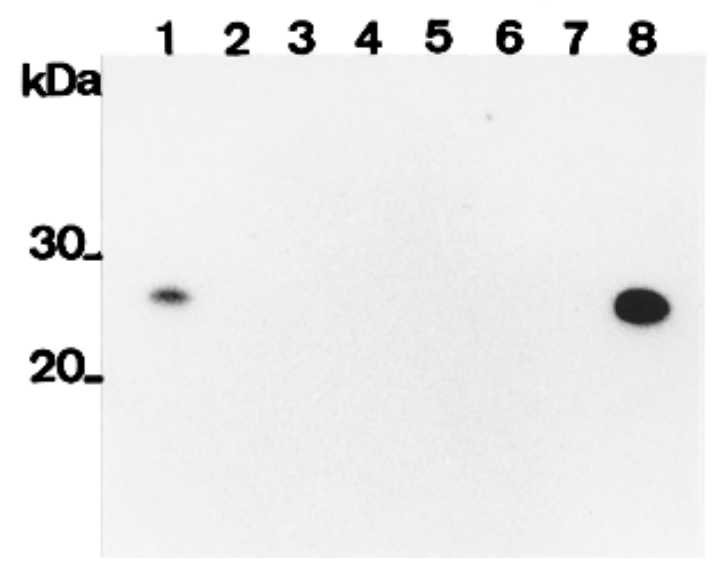

Fig. 4. Western blot detection of green-fluorescent protein (GFP) in Heterodera schachtii and Meloidogyne incognita. Lane 1, M. incognita from GFP-transformed Arabidopsis. Lane 2, M. incognita from wildtype C24 Arabidopsis. Lane 3, H. schachtii from wild-type C24 Arabidopsis. Lane 4, H. schachtii from GFP-transformed Arabidopsis. Lane 8, plant material expressing GFP. Lanes 5, 6, and 7 are blank.

structive sampling for visualization which characterizes most studies based on GUS.

Chloroplasts occur in root cells grown in the light, including the syncytium induced by $H$. schachtii in infected roots of Arabidopsis (Sijmons et al. 1991). Preliminary observation established that chloroplasts occurred in the syncytia but not in the surrounding root cells when plants were grown with only brief exposure to light for observation as described in this work. In uninfected roots grown under high levels of light to induce chloroplasts in a range of cells, the red light emitted by chlorophyll under violet excitation is quenched when GFP is also expressed. Consequently, cells emitting both chlorophyll and GFP-derived fluorescence appear any color in the spectrum from red to green, according to the extent of the effect. Such quenching resulting in a yellow appearance of the emission was previously reported for maize protoplasts (Sheen et al. 1995). The color shift establishes that down-regulation for GFP occurs within 10 days p.i. for syncytia associated with females of $H$. schachtii. The effect is rarely detected for males.

The visual color shift is of value for those lacking image analysis equipment. Our equipment had the advantage of allowing quantification of both increases and decreases in green and red emissions. The green fluorescence emitted from GFP in the light path of the syncytium fell progressively from 10 to 35 days p.i., while the emissions from surrounding cells remained constant. Only a partial reduction in green emissions could be anticipated, even if GFP was absent from the syncytium, because the protein was expressed in the sleeve of cells surrounding this structure. However, the reading at 35 days p.i. was significantly lower than at all other occasions except 31 days p.i. Therefore, GFP was present in the syncytium until at least 27 days p.i. A similar analysis for the red emissions from chlorophyll establishes an increase in this pigment within the syncytium from 7 to 14 days p.i. and approximately constant levels subsequently. The cells surrounding the syncytium maintained a constant low level of red emissions. This presumably represents a background level for red, since these cells lacked obvious chloroplasts.

The GFP reporter system clearly established that the CaMV 
35S promoter was active in the gall tissue surrounding the feeding site of $M$. incognita. The high emission intensity prevented certain detection of expression in giant cells. However, GFP was detected in $M$. incognita by immunoblotting, which provides strong circumstantial evidence for its presence in giant cells. This is consistent with the intense emissions from the region of the giant cells evident in Figure 2G. GFP was not detected in females of $H$. schachtii, although it was present in the syncytium. Microinjection into the syncytium induced by this species has established that $H$. schachtii takes up fluorescent dextrans of 20 but not $40 \mathrm{kDa}$ (Bockenhoff and Grundler 1994). Recent immunoblotting experiments have shown that both $H$. schachtii and $M$. incognita ingest proteinase inhibitors of $11.2 \mathrm{kDa}$ (P. E. Urwin et al., unpublished). This suggests that the exclusion limit for globular proteins in H. schachtii is between 11.2 and $28 \mathrm{kDa}$, whereas the upper limit in $M$. incognita exceeds $28 \mathrm{kDa}$. The site of exclusion of macromolecules by $H$. schachtii may be the feeding tube (Bockenhoff and Grundler 1994). This structure is frequently replaced during feeding (Wyss 1992). Possibly one of its functions is to act as a prefilter, preventing blockage by macromolecules and organelle fragments in the nutrient flow toward the animal. Possibly GFP is not detected in female H. schachtii because it is rapidly degraded by intestinal proteinases. Both cysteine and serine proteinase activities occur in the intestine of Heterodera glycines (Lilley et al. 1996), and a cysteine proteinase activity of $H$. schachtii is inhibited during development on transgenic plants expressing a cystatin (P. E. Urwin et al., unpublished). However, cysteine proteinases also occur in $M$. incognita (unpublished results). Therefore it is more likely that differences in uptake rather than digestive proteinases explain the presence of GFP in $M$. incognita only.

Previous work reported that the CaMV 35S promoter did not provide expression in the gall of $M$. incognita or the syncytium of H. schachtii on Arabidopsis (Goddijn et al. 1993). Even if no GFP is taken up by $H$. schachtii, it seems unlikely that GFP could persist after early down-regulation of the promoter over the time course to 35 days p.i. Therefore we conclude that the CaMV 35S promoter has some activity in the syncytium until at least 27 days p.i. Another possibility is that GFP is actively transported into the feeding cell via the symplastic pathway. If so, it is necessary for GUS not to be imported into the syncytium to fit observations to date. Our results are valid for the CaMV $35 \mathrm{~S}$ promoter derived from the commercially available plasmid pBI 121 (Clontech, Palo Alto, $\mathrm{CA}$ ) but may not apply to other, deleted versions of this promoter that show different responsiveness to nematodes ( $\mathrm{P}$. Burrows, personal communication).

This work establishes the potential of GFP as a reporter system for studying changes in the responsiveness of promoters to nematodes in vivo. Evidence suggests that $H$. schachtii excludes a globular protein of $28 \mathrm{kDa}$. The definition of exclusion limits for different economic nematodes has important implications for the design of any transgenic resistance approach that involves the uptake of proteins by the oral route.

\section{MATERIALS AND METHODS}

Plant transformation.

The construct pBI121 CaMV35S-mGFP was kindly provided by J. Haseloff, MRC, Cambridge. The $g f p$ gene in this construct had been modified to remove the cryptic splice sites in the encoded protein, to allow expression in Arabidopsis (Hasseloff and Amos 1995). The construct was electroporated into Agrobacterium tumefaciens (Shen and Forde 1989) and introduced into Arabidopsis thaliana ecotype C24 by $A$. tumefaciens-mediated transformation of roots as described by Clarke et al. (1992). T1 seed was collected from individual plants; Aracons (Beta-Tech, Gent, Belgium) were used to ensure self-fertilization.

\section{Plant growth.}

To facilitate continual microscopic examination of roots, plants were effectively grown in "two dimensions" between glass plates $(200 \times 180 \mathrm{~mm})$ (Fig. 1). Three plastic spacers (1.5 mm thick) were placed at the sides and bottom edge of a glass plate, and a fourth spacer was placed approximately 5 $\mathrm{cm}$ from the top edge. MS medium $(0.5 \times)$ supplemented with $1 \%$ sucrose and $0.4 \%$ phytagel (Sigma Chemical Co., Dorset, U.K.) was poured on the plate between the spacers and allowed to set, and then the fourth spacer was removed. A 10- to 14-day-old Arabidopsis plant grown in a petri dish containing the medium described above was placed on the plate with only the roots on the medium and the aerial tissue in the top quarter of the plate. Where appropriate, the roots were then infected with nematodes. Another set of three spacers (1.5 mm thick) was added on top of the first set, followed by a second glass plate. The sides and bottom were sealed with waterproof tape and the top edge with micropore tape. The lower three quarters of the cassette, containing the medium and the roots, was covered with aluminum foil to prevent exposure to light, and the plates were held together with small fold-back clips (Fig. 1). On initial observation of a root system, no chloroplasts were apparent. However, on subsequent observations, chloroplasts had developed in syncytia, because the root systems had been exposed to light during examination. These cassettes were stored vertically in Sanyo MLR3500 growth cabinets with a 16-h day length and light intensity at $6 \mu \mathrm{mol} \mathrm{sec}^{-1} \mathrm{~m}^{-2}$.

\section{Nematode infection.}

Eggs of $M$. incognita were recovered from stock colonies (ex Imperial College, London) and set to hatch as described by Atkinson et al. (1996). Cysts of H. schachtii (ex Maribo, Denmark) and second-stage juveniles (J2s) were surfacesterilized before use. Cysts were incubated in $0.1 \%$ malachite green for $30 \mathrm{~min}$ at room temperature and rinsed in running tap water for $1 \mathrm{~h}$ prior to soaking overnight at $4^{\circ} \mathrm{C}$ in an antibiotic cocktail containing streptomycin sulfate $\left(8 \mathrm{mg} \mathrm{ml}^{-1}\right)$, penicillin $\mathrm{G}\left(6 \mathrm{mg} \mathrm{ml}^{-1}\right)$, polymyxin $B\left(6.13 \mathrm{mg} \mathrm{ml}^{-1}\right)$, tetracycline $\left(5 \mathrm{mg} \mathrm{ml}^{-1}\right)$, and amphotericin $\mathrm{B}\left(1 \mathrm{mg} \mathrm{ml}^{-1}\right)$. The cysts were washed and set to hatch in filter-sterilized tap water. An overnight hatch of J 2 s was counted and sterilized sequentially for 5-min periods with each of the following antibiotics: $0.1 \%$ streptomycin sulfate, $0.1 \%$ penicillin $\mathrm{G}$, $0.1 \%$ amphotericin $\mathrm{B}$, and $0.1 \%$ cetyltrimethylammonium bromide (Cetrimide, Sigma). J2s were collected by microcentrifugation for $10 \mathrm{~s}$ between treatments and were finally washed extensively in filter-sterilized tap water before use.

A $10-\mu \mathrm{l}$ aliquot containing $100 \mathrm{~J} 2 \mathrm{~s}$ of $H$. schachtii or $M$. incognita was pipetted onto the roots of an individual Arabidopsis plant. 


\section{Image capture and analysis.}

Bright-field images were viewed with a Leica microscope (model DMRB), and fluorescent images were viewed with an Olympus microscope (model $\mathrm{BH} 2$ ) at an excitation wavelength of 395 to $415 \mathrm{~nm}$ (violet light) and a cut-off emission filter at $495 \mathrm{~nm}$. Images for analysis were captured with a color camera (Kappa CF15 MCC) mounted on the Olympus microscope. The camera output was connected to a frame grabber, and analysis was controlled through a software package (Leica Quantimet 500+C). The captured measurements were transferred to a cascaded window of a spreadsheet (Microsoft Excel 5) by the use of a macro routine. Data sets were saved as worksheets and subsequently transferred to a statistical package (Statistical Package for the Social Sciences, SPSS Inc., Chicago, IL) resident on the hard drive of the computer. This was used to carry out regression and oneway ANOVA (Snedecor and Cochran 1989).

\section{Detection of GFP by Western blot analysis.}

Adult females of $H$. schachtii and $M$. incognita were removed from either C24 wild-type or transgenic Arabidopsis plants expressing GFP and placed in water. Samples of $H$. schachtii comprising 40 individuals were collected from each C24 or GFP-expressing Arabidopsis. Two similar-sized samples of $M$. incognita were collected. The nematodes were homogenized in a microcentrifuge tube using a plastic pestle. The soluble protein fraction was collected by centrifugation $(13,000 \times g$ for $10 \mathrm{~min})$ in $20 \mu \mathrm{l}$ of $0.5 \times$ phosphate-buffered saline and subjected to Western blot analysis. An anti-GFP primary antibody (Clontech, U.K.) and an anti-rabbit secondary antibody conjugated with horseradish peroxidase were used, and detection of positive samples was carried out by HRPL (Horseradish Peroxidase Luminescent Visualization System) according to the manufacturer's instructions (National Diagnostics, Atlanta, GA).

\section{ACKNOWLEDGMENTS}

This work was supported by funding from the Biotechnology and Biological Sciences Research Council, Scottish Office Food and Agriculture Department, and Hilleshög N.K. S. G. Møller is the recipient of a Norwegian Research Council stipend and Overseas Research Scholarship Award. We thank J. Hasseloff for providing the mGFP clone and J. Goodall and C. Sharpe for technical assistance. This work was performed under Ministry of Agriculture, Fisheries and Food authorization no. PHF/1568/1767.

\section{LITERATURE CITED}

Atkinson, H. J. 1993. Opportunities for improved control of plant parasitic nematodes via plant biotechnology. Pages 257-266 in: Opportunities for Molecular Biology in Crop Production. D. J. Beadle, D. H. L. Bishop, L. G. Copping, G. K. Dixon, and D. W. Holloman, eds. British Crop Protection Council, Farnham, Surrey, UK.

Atkinson, H. J. 1995. Pathogenesis and host specificity in plant diseases. Pages 355-370 in: Histopathological, Biochemical, Genetic and Molecular Bases Diseases. Vol. 2: Eukaryotes. K. Kohmoto, U. S. Singh, and R. P. Singh, eds. Pergamon Press/Elsevier, Oxford.

Atkinson, H. J., and Lilley, C. J. 1997. Promoters for control of rootfeeding nematodes. U.K. application no. 9524395.2.

Atkinson H. J., Urwin, P. E., Clarke, M. C., and McPherson, M. J. 1996. Image analysis of the growth of Globodera pallida and Meloidogyne incognita on transgenic tomato roots expressing cystatins. J. Nematol. 28:209-215.

Bird, D. M., and Wilson, M. A. 1994. DNA sequence and expression analysis of root-knot nematode-elicited giant cell transcripts. Mol. Plant-Microbe Interact. 7:419-424.

Bockenhoff, A., and Grundler, F. M. W. 1994. Studies on the nutrient uptake by the beet-cyst nematode Heterodera schachtii by in-situ micro injection of fluorescent-probes into the feeding structures in Arabidopsis thaliana. Parasitology 109:249-255.

Clarke, M. C., Wei, W., and Lindsey, K. 1992. High frequency transformation of Arabidopsis thaliana by Agrobacterium tumefaciens. Plant Mol. Biol. Rep. 10:178-189.

Goddijn, O. J. M., Lindsey, K., van der Lee, F., Klap, J. C., and Sijmons, P. C. 1993. Differential gene expression in nematode induced feeding structures of transgenic plants harbouring promoter-gusA fusion constructs. Plant J. 4:863-873.

Gurr, S. J., McPherson, M. J., Scollan, C., Atkinson, H. J., and Bowles, D. J. 1991. Gene expression in nematode infected plant roots. Mol. Gen. Genet. 226:361-366.

Hague, N. G. H., and Gowen, S. R. 1987. Chemical control of nematodes. Pages 131-178 in: Principles and Practice of Nematode Control in Crops. R. H. Brown and B. R. Kerry, eds. Academic Press, Sydney.

Hammond-Kosack, K., Atkinson, H. J., and Bowles, D. J. 1989. Local and systemic changes in gene expression in potato plants following root infection with cyst nematode Globodera rostochiensis. Physiol. Mol. Plant Pathol. 37:339-354.

Hansen, E., Harper, G., McPherson, M. J., and Atkinson, H.J. 1996. Differential expression patterns of the wound-inducible transgene wunluidA in potato roots following infection with either cyst or root-knot nematodes. Physiol. Mol. Plant Pathol. 48:161-170.

Hasseloff, J., and Amos, B. 1995. GFP in plants. Trends Genet. 11:328329.

Lambert, K. N., and Williamson, V. M. 1993. cDNA library construction from small amounts of RNA using paramagnetic beads and PCR. Nucleic Acids Res. 21:775-776.

Lilley, C. J., Urwin, P. E., McPherson, M. J., and Atkinson, H. J. 1996. Characterisation of intestinally active proteinases of cyst-nematodes. Parasitology 113:415-424.

Opperman, C. H., Taylor, G. C., and Conkling, M. A. 1994. Root-knot nematode directed expression of a plant root-specific gene. Science 263:221-223.

Sheen, J., Hwang, S., Niwa, Y., Kobayashi, H., and Galbraith, D. W. 1995. Green-fluorescent protein as a new vital marker in plant cells. Plant J. 8:777-784.

Shen, W., and Forde, B. G. 1989. Efficient transformation of Agrobacterium spp. by high voltage electroporation. Nucleic Acids Res. 17: 8385.

Sijmons, P. C., Atkinson, H. J., and Wyss, U. 1994. Parasitic strategies of root nematodes and associated host cell responses. Annu. Rev. Phytopathol. 32:235-259.

Sijmons, P. C., Grundler, F. M. W., von Mende, N., Burrows, P. R., and Wyss, U. 1991. Arabidopsis thaliana as a new model host for plantparasitic nematodes. Plant J. 1:245-254.

Sijmons, P. C., von Mende, N., and Grundler, F. M. W. 1994. Plant parasitic nematodes. Pages 749-768 in: Arabidopsis. E. M. Meyerowitz and C. R. Somerville, eds. Cold Spring Harbor Laboratory Press, Cold Spring Harbor, NY

Snedecor, G. W., and Cochran, W. G. 1989. Statistical Methods. Iowa State University Press, Ames.

Urwin, P. E., Atkinson, H. J., Waller, D. A., and McPherson, M. J. 1995. Engineered oryzacystatin-I expressed in transgenic hairy roots confers resistance to Globodera pallida. Plant J. 8:121-131.

Van der Eycken, W., de Almeida Engler, J., Inzé, D., Van Montagu, M., and Gheysen, G. 1996. A molecular study of root-knot nematodeinduced feeding sites. Plant J. 9:45-54.

Wilson, M. A., Bird, D. M., and van der Knaap, E. 1994. A comprehensive subtractive cDNA cloning approach to identify nematodeinduced transcripts in tomato. Phytopathology 84:299-303.

Wyss, U. 1992. Observations on the feeding behaviour of Heterodera schachtii throughout development, including events during moulting. Fundam. Appl. Nematol. 15:75-89. 